\title{
A Prospective Study on Incidence, Etiopathogenesis, Clinical Presentation, Management And Prognosis of Liver Abscess in 100 Cases
}

\author{
Dr.P.Sumathi MS Gen Surg ${ }^{1}$, DGO,Dr.G.Rajashok MS Gen Surg ${ }^{2}$ \\ Department Of General Surgery, Government Mohan Kumaramangalam Medical College Hospital, Salem, \\ Tamil Nadu, India
}

\begin{abstract}
Liver abscess ccan be a potentially life threatening condition requiring immediate intervention. It can be pyogenic or amoebic. The aim of this study is to know about the incidence,etiopathogenesis,clinical presentation and prognosis of 100 cases of liver abscess alng with comparison of USG guided aspiration vs USG marked site aspiraton of liver abscess at bedside.Amoebic liver abscess is the commonest extraintestinal manifestation of amoebiasis. This study was from June 2014 to November 2015.incidence was higher in $4^{\text {th }}$ decade and in men. Alcohol intake had a strong association with amoebic liver abscess. Abdomen pain was present in all.right lobe was commonly involved. USG marked site aspiration needed multiple punctures with residual collection wheras USG guided aspiration was a single sitting single puncture procedure. On table USG may be needed in cas of multiple abscess with one alone ruptured.
\end{abstract}

Keywords : Amoebiasis ,Liver abscess, Pyogenic,USG guided.

\section{Introduction}

Liver abscess continues to be a major diagnostic and therapeutic challenge to the medica; fraternity. It is a life threatening and a potentially serious condition if left unteated. Two types of liver abscess are pyogenic and amoebic liver abscess. Amoebic liver abscess is the commonest extra intestinal manifestation of amoebiasis. It occurs in $3-9 \%$ of victims.it may present as acute abdomen or apontaneous rupture. Pyogenic liver abscess is a rare complication of intra abdominal infection or biliary tract infrction.it is ascending type polymicrobial infection.

\section{Aim Of The Study}

1. To study the incidence and etiology of liver abscess

2. To evaluate its clinical features

3. To compare the results of USG guided aspiration vs USG marked site bedside aspiration.

4. To study the management and prognosis of liver abscess

\section{Materials And Methods}

It is a prospective study in 100 cases of liver abscess presenting in Government Mohan Kumaramangalam Medical College Hospital from june 2014 to November 2015.

\section{Exclusion Criteria}

1. Hydatid liver cyst

2. Solid masses of the liver

3. Primary and secondary malignancies of the liver

\section{Results}

Table 1 Age Incidence

\begin{tabular}{|l|l|l|}
\hline Age Group In Yrs & No.Of Patients & Percentage \\
\hline $30-40$ & 16 & 16 \\
\hline $41-50$ & 49 & 49 \\
\hline $51-60$ & 20 & 20 \\
\hline$>60$ & 15 & 15 \\
\hline
\end{tabular}

Table 2 Sex Distribution

\begin{tabular}{|l|l|l|}
\hline Sex & No.of patients & Percentage \\
\hline Male & $\mathbf{9 7}$ & $\mathbf{9 7}$ \\
\hline Female & $\mathbf{3}$ & $\mathbf{3}$ \\
\hline
\end{tabular}


Table 3 History Of Alcohol Intake In Liver Abscess

\begin{tabular}{|l|l|l|}
\hline Alcohol Intake & No.Of Patients & Percentage \\
\hline Amoebic & $\mathbf{5 8}$ & $\mathbf{5 8}$ \\
\hline Pyogenic & $\mathbf{3}$ & $\mathbf{3}$ \\
\hline
\end{tabular}

Table 4 Symptoms Among Cases Of Liver Abscess

\begin{tabular}{|l|l|l|}
\hline Symptoms & No.Of Patients & Percentage \\
\hline Abdomen Pain & 99 & 99 \\
\hline Fever & 57 & 57 \\
\hline Abdominal Distension & 51 & 51 \\
\hline Dysentry & 16 & 16 \\
\hline
\end{tabular}

Table 5 Signs Of Liver Abscess

\begin{tabular}{|c|c|c|}
\hline Signs & No.Of Patients & Percentage \\
\hline R Hypochondrial Tenderness & 100 & 100 \\
\hline Intercostal Tenderness & 100 & 100 \\
\hline Hepatomegaly & 50 & 50 \\
\hline Jaundice & 25 & 25 \\
\hline Epigastric Mass & 12 & 12 \\
\hline
\end{tabular}

Table 6 lobe involvement and no. Of abscesses

\begin{tabular}{|l|l|l|}
\hline Presentation & No.Of Patients & Percentage \\
\hline Right Lobe Single & 45 & 45 \\
\hline Right Lobe Multiple & 25 & 25 \\
\hline Left Lobe Single & 8 & 8 \\
\hline Left Lobe Multiple & 2 & 2 \\
\hline Both Lobes & 6 & 6 \\
\hline
\end{tabular}

Table 7 Etiology Of Liver Abscess

\begin{tabular}{|l|l|l|}
\hline Presentation & No.Of Patients & Percentage \\
\hline Amoebic & 86 & 86 \\
\hline Pyogenic & 14 & 14 \\
\hline
\end{tabular}

Table 8 Mode Of Treatment Of Liver Abscess

\begin{tabular}{|l|l|l|}
\hline Treatment & No.Of Patients & Percentage \\
\hline Single Aspiration & 30 & 30 \\
\hline Percutaneous Catheter Drainage & 25 & 25 \\
\hline Laprotomy And Drainage & 22 & 22 \\
\hline Multiple Aspiration & 19 & 19 \\
\hline Laproscopic Aspiration & 1 & 1 \\
\hline Conservative Mangement & 3 & 3 \\
\hline
\end{tabular}

\section{Discussion}

Liver abscess can be amoebic or pyogenic. First one is usually caused by entameba histolytica . asymptomatic carrier state occurs in E.dispar. pyogenic can be due to various microorganisms ranging from E.coli , klebsiella,proteus, enterobacter to staphylocoocus, bacteriodes, fusobacterium. Pathogenesis is due to one of the following. Ascending cholangitis, pylephlebitis, hepatic artery septicaemia,traumatic,cryptogenic.Patients present with hypochondrial pain,, nausea vomiting, sweating, rigors, diarrhoea. Diagnostic modalities include chest xray raised right hemidiaphragm,USG or CT showing space occupying lesion,liver aspirate,positive indirect hemagglutinin of serum antibodies .Complications include rupture, peritonitis,[paralytiv ileus, hemobilia, secondary bacterial infection,metastatic brain abscess. Treatment for amoebic abscess includes amoebicidal,luminicidal agents along with percutaneous drainage which can be USG guide or USG marked site drainage.

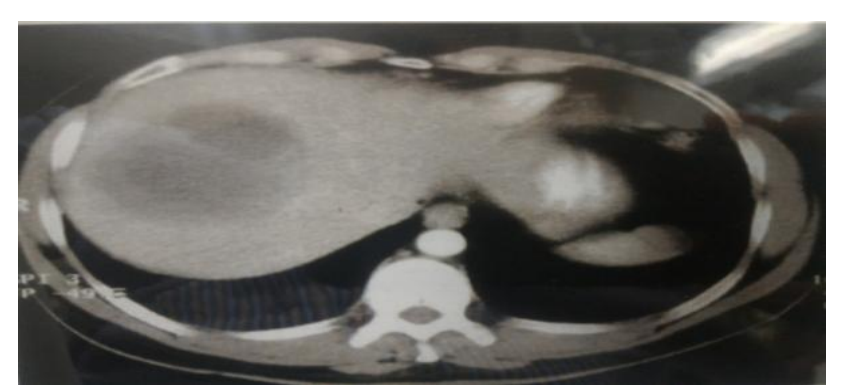

Fig 1 ct scan showing liver abscess 


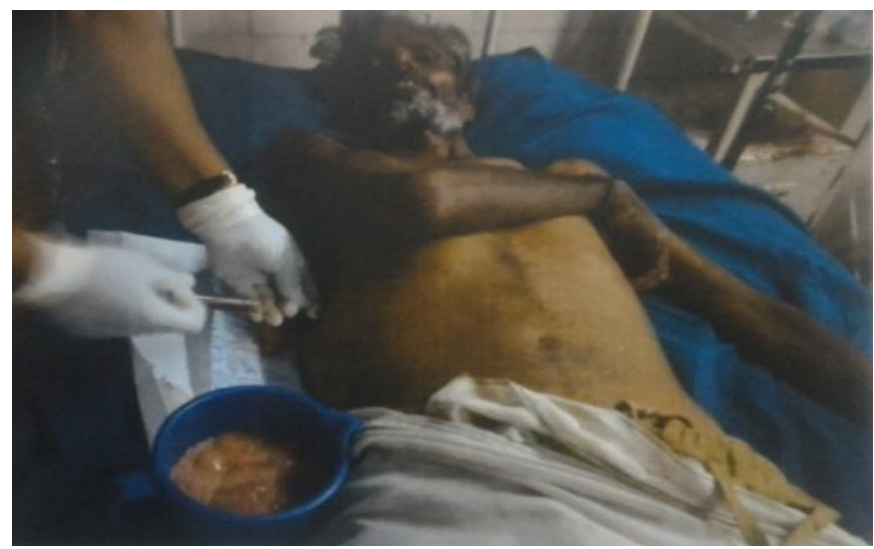

Fig2 percutaneous aspiration of liver abscess

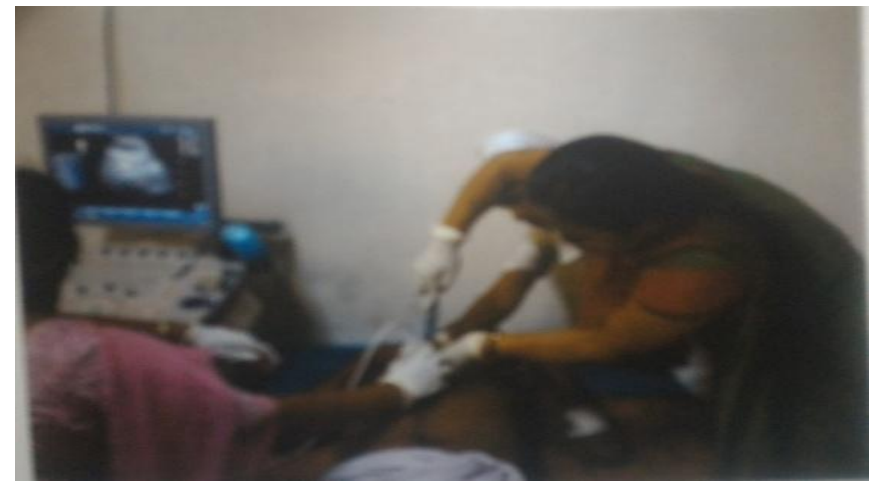

Fig 3 USG guided aspiration of liver abscess

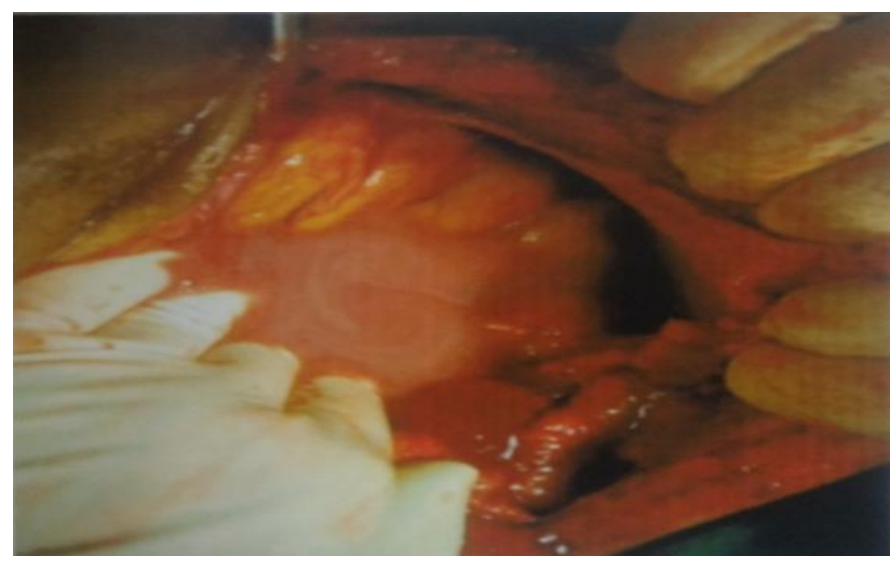

Fig 4 laprotomy showing ruptured liver abscess

\section{Conclusion}

Liver abscess constitutes $0.29 \%$ of total surgical ward hospitalisation per year Common in $4^{\text {th }}$ decade in men Associated with alcohol intake in $2 / 3^{\text {rd }}$ cases Majority of cases are amoebic E.coli is the commonest organism causing pyogenic abscess Abdominal pain is the commonest symptom Right hypochondrial tenderness is the commonest sign Right lobe was predominantly involved Percutaneous aspiration under USG guide technique gave better results than USG marked site aspiration which resulted inresidual collectionand multiple aspirations. On table USG may be needed in multiple abscess with one alone gone for rupture.

\section{References}

[1]. Raolekha et al management of pyogrnic liver abscess department of general surgery university of limpopo

[2]. memon as et al management of ruptured liver abscess 22 years experienxe abbotabad]

[3]. B.D. chaurasia text book of human anatomy volume $25^{\text {th }}$ edition

[4]. Sabiston text book of surgery $18^{\text {th }}$ edition volume 2.

[5]. meingott abdominal operation 11 th edition

[6]. Ananthakrishnan ramani et al USG guided needle aspiration of amoebic liver abscess. 